\title{
Mangelernährung bei Kindern auf der Spur
}

\section{Erlanger Ernährungskonvent}

" Mehr Aufmerksamkeit für den Ernährungszustand besonders von chronisch kranken Kindern forderten Experten aus Klinik und Praxis, Ernährungsspezialisten und Vertreter von Pflege und Politik beim 3. Erlanger Ernährungskonvent. Ein besonders hohes Risiko für einen schlechten Ernährungszustand haben Frühgeborene und chronisch kranke Kinder. Die Folgen einer Mangelernährung können gravierend sein: Es kann u.a. zu Wachstumsstörungen, verminderter Gehirnentwicklung, erhöhter Infektanfälligkeit und einer verschlechterten neuromuskulären Entwicklung kommen.
Für einen individualisierten Ansatz bei der Ernährung akut und chronisch kranker Kinder setzt sich das Erlanger Unternehmen Nutricia ein. Es bietet dafür altersadaptierte pädiatrische Trink- und Sondennahrung, die speziell auf den individuellen Nährstoffbedarf von Kindern zugeschnitten ist. Die Infatrini ${ }^{\circledR}$-Produkte umfassen Trink- und Sondennahrung für Säuglinge. Für Kinder in den unterschiedlichen Entwicklungsphasen stehen verschiedene Varianten der Marke Nutrini ${ }^{\circledR}$ zur Verfügung. Auf der Internetseite von Nutricia sind auch Hinweise zur Arzneimittelrichtlinie bezüglich

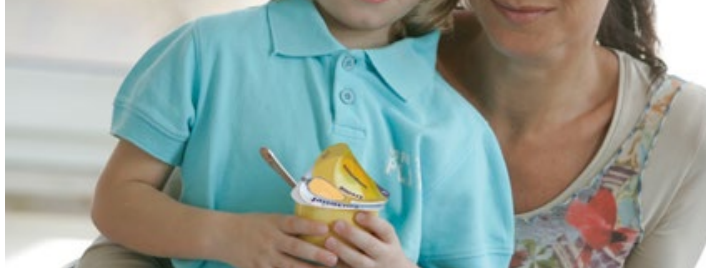

der Erstattung von medizinischer Ernährung zu finden. Zusätzlich bietet Nutricia einen deutschlandweit einmaligen Service an: Die MEHRnährungsexperten Junior unterstützen Eltern, Angehörige und Pflegekräfte von Kindern, die auf Trink- und/oder Sondennahrung angewiesen sind. Erfahrene, examinierte Pflegekräfte helfen unter anderem bei der Integration der Ernährungstherapie in den Familienalltag.

www.nutricia.de

\section{Patientenmanagement bei Krankenhausinfektionen}

\section{Molekulare Diagnostik bietet schnelle Ergebnisse}

") Krankenhausinfektionen, insbesondere durch multiresistente Erreger, nehmen zu. Dabei geht es insbesondere darum, solche mittels ScreeningMethoden frühzeitig zu erkennen, um dann durch geeignete Maßnahmen Transmissionen und Infektionen $\mathrm{zu}$ verhindern. Vorteilhaft sind molekulare Verfahren wie die Polymerasekettenreaktion (PCR). „Die PCR-Technologie zeichnet sich durch eine sehr hohe Spezifität und Sensitivität und eine deutlich kürzere Turn-around-Zeit aus“, erläuterte Dr. Oliver Liesenfeld, Chief Medical Officer von Roche Molecular Systems. Gerade für das MRSAScreening sei es wichtig, dass das Ergebnis sehr schnell vorliege. Bei einer molekularen Diagnostik ist das nach max. 30 Minuten der Fall. Bei den chromogenen Kulturmedien vergehen dagegen mindestens 24 Stunden.

Mit dem neuen cobas $^{\circledR}$ Liat $^{\circledR}$ System steht jetzt eine leicht $\mathrm{zu}$ bedienende Molekulardiagnostikplattform zur Verfügung. „Das handliche System erleichtert die Diagnose von Infektionskrankheiten und erlaubt zentral und dezentral schnelle Entscheidungen", so Liesenfeld. Innerhalb kurzer Zeit könne das Labor Einzelproben auch außerhalb der üblichen Betriebszeiten und auch in Außenstellen wie dem NotfallLabor bearbeiten. Das ermögliche Ärz- ten, schnelle Therapieentscheidungen treffen und entsprechende Hygienemaßnahmen einleiten zu können.

Das Test-Portfolio umfasst zurzeit Influenza A/B, Influenza A/B + RSV, Strep A und Clostridium difficile. In $a b$ sehbarer Zeit wird MRSA/SA folgen und HIV qual. ist in der Entwicklung. Im Vergleich zur Virenkultur und IFAFärbung beträgt die Sensitivität bei Influenza A/B Test 100\% bei einer Spezifität von $96,8 \%$ bei Influenza $A$ und $94,2 \%$ bei Influenza B. „Die gleichzeitige Detektion und Differenzierung von Influenza A und B in einem Test mit einem zuverlässigen Ergebnis bereits nach 20 Minuten ist ein großer Fortschritt", so Liesenfeld. Darüber hinaus bietet cobas ${ }^{\circledR}$ Liat $^{\circledR}$ ein umfangreiches Kontroll- und Sicherheitskonzept. (sti)

Satellitensymposium „cobas Liat: Schnelle Antworten - damit Infektionen sich nicht ausbreiten" im Rahmen der gemeinsamen Jahrestagung der Deutschen Gesellschaft für Hygiene und Mikrobiologie (DGHM) und der Vereinigung für Allgemeine und Angewandte Mikrobiologie (VAAM); Würzburg, 6.3.2017 (Veranstalter: Roche Diagnostics Deutschland $\mathrm{GmbH}$ )

\section{Gesetzesänderung zur Wundversorgung}

\section{Hydroaktive Wundverbände jetzt erstattungsfähig}

» Mit der aktuellen Gesetzesänderung zur Wundversorgung im Heil- und Hilfsmittelversorgungsgesetz (HHVG) hat der Gesetzgeber eine Definition für Verbandmittel geschaffen, die die meisten etablierten Verbandmittel einschließt. Das Fehlen einer Definition führte in den letzten Jahren zu Konflikten über die Erstattung spezieller Wundauflagen. Der Gesetzgeber sichert jetzt auch die Erstattung für Wundverbände zur hydroaktiven Wundbehandlung. Verbandmittel können zusätzlich zu ihrer bedeckenden und aufsaugenden Wirkung weitere Funktionen zur Unterstützung der Wundheilung haben.

www.info-wundversorgung.de 